\title{
Estimation neutre pour les personnes morales
}

\section{8.}
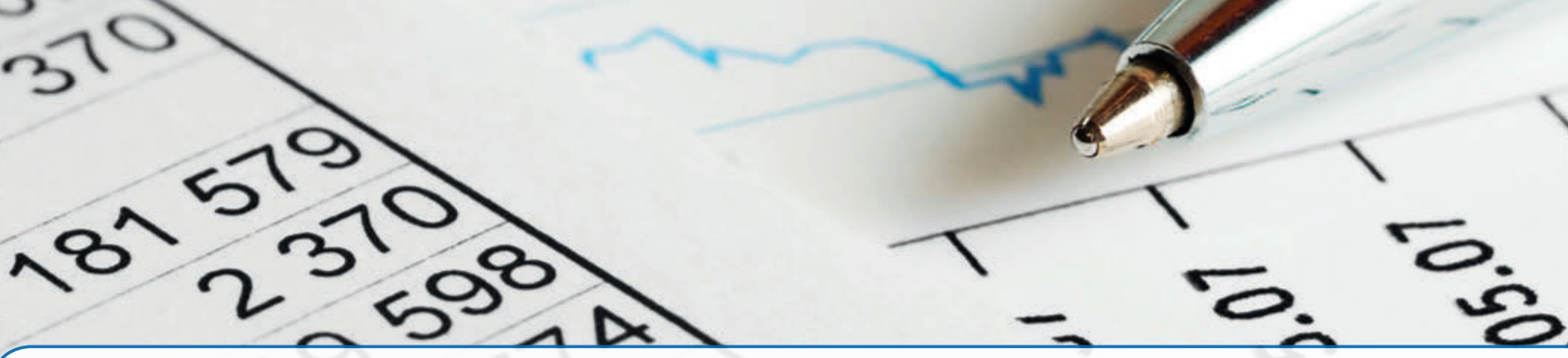

En cas d'arrivée, de départ, de recherche ou de séparation d'un associé du cabinet

- estimation neutre de l'entreprise (inventaire, goodwill, valeur des actions)

- rapport qualité-prix attrayant

- leader sur le marché, longue expérience et compétences largement reconnues dans l'estimation de tous types de cabinets médicaux

\section{ESTIMATION NEUTRE POUR LES PERSONNES MORALES}

\section{T. FMH SERVICES}

Vous pouvez prendre contact avec nous sans aucune obligation par téléphone ou courrier électronique ou en nous retournant le talon-réponse par fax ou par la Poste. Nous vous contacterons.

Prénom / nom

Adresse

NPA / lieu

Téléphone privé / prof.

Atteignable de préférence vers

Adresse mail
CONSULTING

FMH Consulting Services AG

Avenue d'Ouchy 66, 1006 Lausanne

Tél. 0219224435 - Fax 0419250067

mail@fmhconsulting.ch - www.fmhservices.ch 